\title{
The Economic Connectivity in Transportation and Tourism Supply Chain of Loei, Thailand-Laos PDR-Social Republic of Vietnam - Republic of China
}

\section{Pichit Prapinit and 2 Mustakim Melan}

${ }_{1}$ Loei Rajabhat University Thailand.

${ }_{2}$ Universiti Utara Malaysia.

Correspondence Author: Pichit Prapinit, Loei Rajabhat University Thailand.

Received date: 22 December 2017, Accepted date: 22 January 2018, Online date: 5 February 2018

Copyright: (C) 2018 Pichit Prapinit. This is an open-access article distributed under the terms of the Creative Commons Attribution License, which permits unrestricted use, distribution, and reproduction in any medium, provided the original author and source are credited.

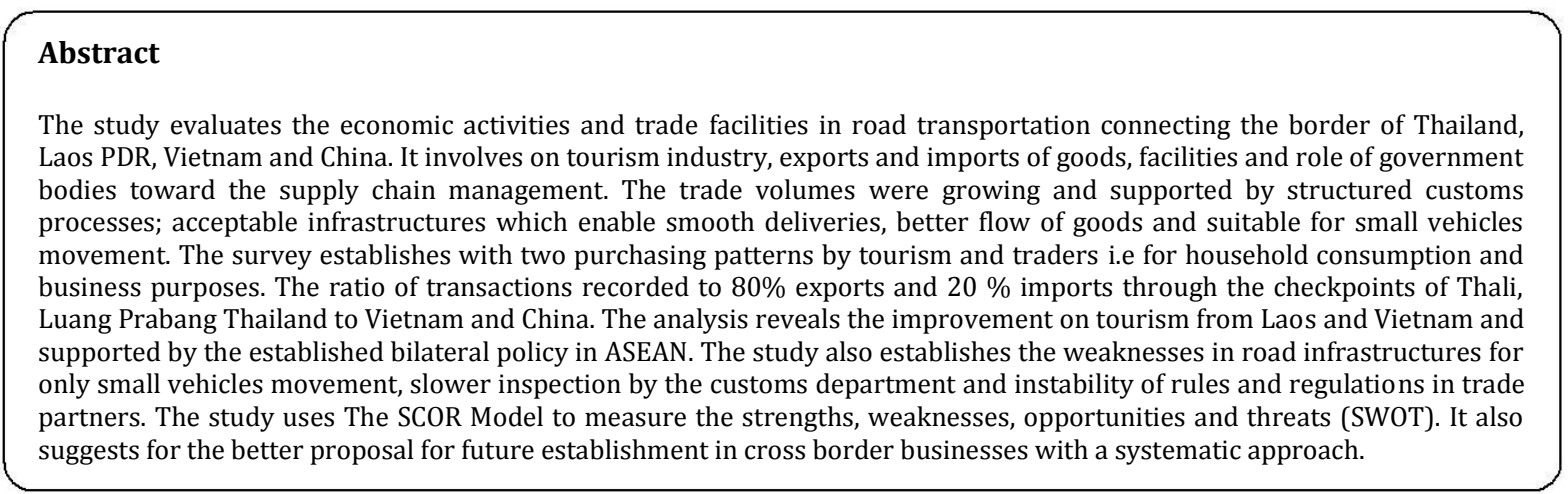

Key words: Transportation, tourism, Economic Connectivity, businesses, supply chain management

\section{INTRODUCTION}

The Greater Mekong Sub Region Cooperative Framework has been jointly established by six countries namely Thailand, Myanmar, Laos, Cambodia, Vietnam and Southern China along three significant economic corridors including the North-South Economic Corridor, the East-West Economic Corridor, and the Southern Economic Corridor. The cooperation is fostered by the commencement of the ASEAN Economic Community (AEC) by the end of the year 2015. Besides, this group of countries has high potential for economic growth, particularly the countries on the Indochina Peninsular namely Cambodia, Laos, Myanmar and Vietnam generally known as CLMV. This will resulted in the improvement of the road transportation from Loei province to the Northern provinces of Laos through to Southern China and Vietnam. The route can potentially be developed into the East-West Corridor beginning from Thali district in Loei to Sayabouly province's Paklay city, Luang Prabang province and Xiangkhouang Province in Laos to Hanoi and Southern China. It is a new economic route with great economic opportunities as shown in Figure 1: In fact, Loei is one of the Thai provinces that are significant to the country in terms of the Thai-Lao trade, be it border trade, cross-border trade or transit trade. The trade volume for goods, especially Tourism, and services has increased year on year on the ground that consumers in Laos and Vietnam have a positive attitude towards the Thai goods. These consumers view that the goods manufactured in Thailand are of better quality than those produced in China. It is, therefore, a good opportunity for Thailand to export Tourism to Laos, Vietnam and possibly China. 


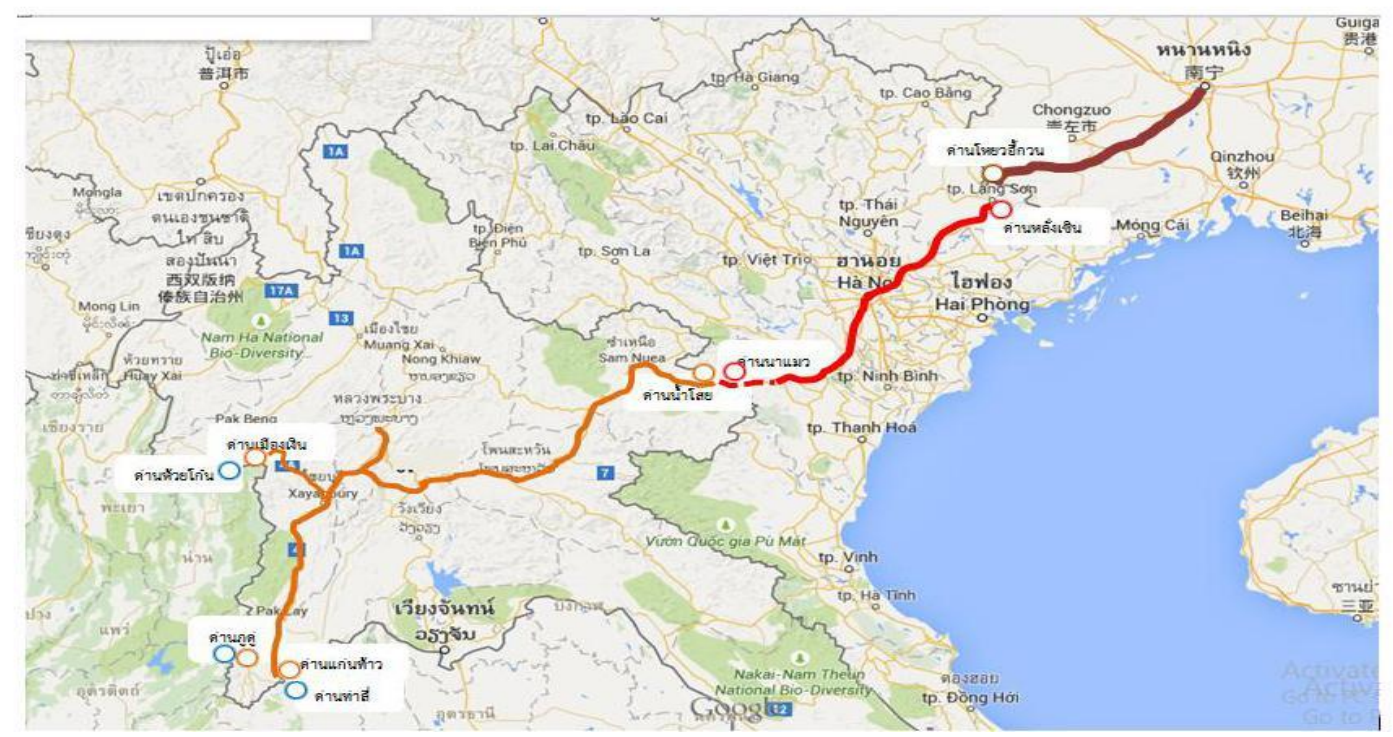

Fig. 1: The studied trade route (Pichit, 2015,p.84)

\section{Methodology:}

In this study, the researchers employed both quantitative and qualitative approaches by conducting a survey on the economic conditions as well as on the route used to transport goods from Loei's Thali district to Laos, Vietnam and China. A survey on the economic connectivity and trade route was carried out to understand the actual current conditions of the Tourism supply chain using the evaluation model for economic and trade facilitation as the external process which partly enhances the effectiveness of the supply chain management based on the fact that, with suitable trade facilitation, the amount of time and cost required for the transportation process will be reduced (Larry, 2000). In this study, four trade facilitation factors were determined as follows;

2.1 The speed of the customs procedures

2.2 The readiness of the economic infrastructure that encourages speedy delivery of goods and service such as the basic economic structure, the road conditions and the driving conditions on the route

2.3 The rules and regulations that are conductive to business operations

2.4 The use of technologies namely e-customs and e-business

Performance Measurement in Tourism Supply Chain from the SCOR model:

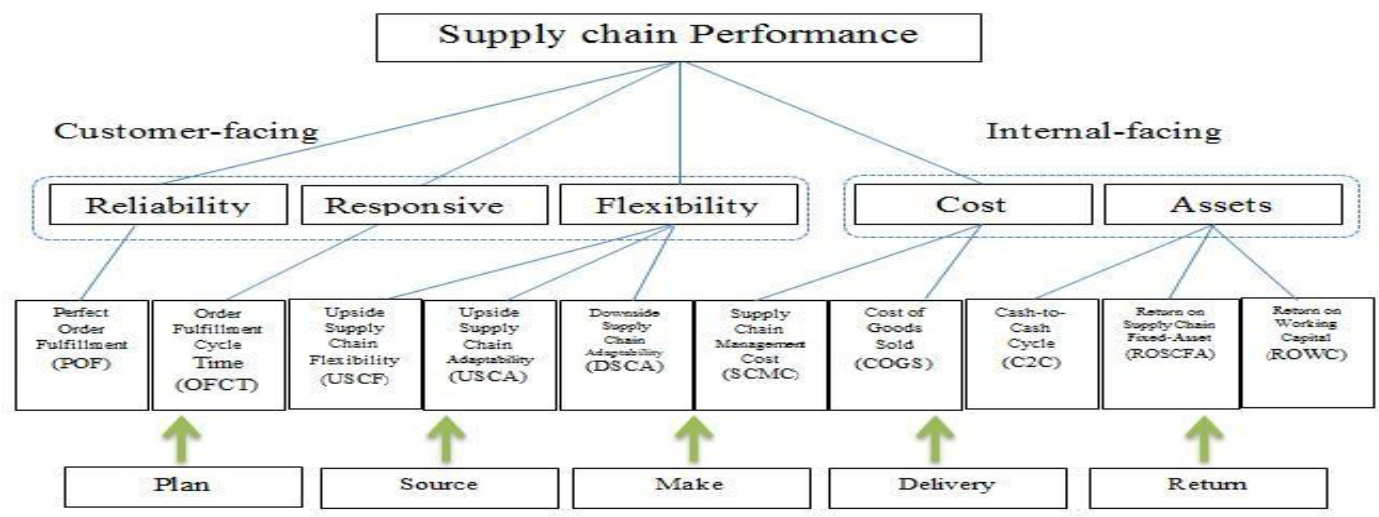

Fig. 2: Supply chain Performance Measurement [3]

In 1996, the Supply Chain Operation Reference Model (SCOR) was developed by Supply Chain Council as the supply chain process standards in measuring the performance of the supply chain process. Five supply chain activities were categorized namely planning, sourcing, making, delivery and return. These activities divided the performance measurement into five criteria including reliability, responsiveness, flexibility, supply chain cost and supply chain asset management [4]. In-depth interviews with those involved in the Tourism supply chain including state authorities and business operators were conducted in order that strengths, weaknesses, opportunities and threats were identified using the SWOT analysis and the guideline on future development of the Tourism supply chain for Loei province, Laos, Vietnam and China as the tools. A similar study was carried out in measuring the congestion at border checkpoints of Bukit Kayu Hitam and Sadao Thailand [5]

\section{RESULTS AND DISCUSSIONS}

The Economic connectivity, customs procedures, technology, rules and regulation are the main issues in the study. It supposed to be developed to ensure continues of the bilateral trades at border areas. The general conditions of Loei province's Tourism supply chain household consumption border to purchase goods as wholesale and to sell on back in their country. It is good in term of economic growth for Thailand. The of the demand through strengths, weaknesses, opportunity and threats were also measured and appropriate action had been taken for improvement.

3.1 The Economic connectivity, customs procedures, technology, rules and regulation:

The economic connectivity of the Tourism of Loei province, Laos, Vietnam and China presents a chance for economic expansion with high connectivity, particularly for the import and export of Tourism and tourism. As for the customs procedures, the speed is at the moderate level. Regarding the infrastructure, the readiness of the economic infrastructure that promotes the speed of goods delivery such as roads conditions and driving conditions on the route is at the moderate level. With regard to rules and regulations, the rules and regulations in Laos which facilitate business operations are more conductive to the transportation of goods 
than those in Vietnam and China. Concerning the use of technologies including e-customs and e-business, the customs checkpoints in China make use of the most modern technologies in comparison to those employed in the other three countries.

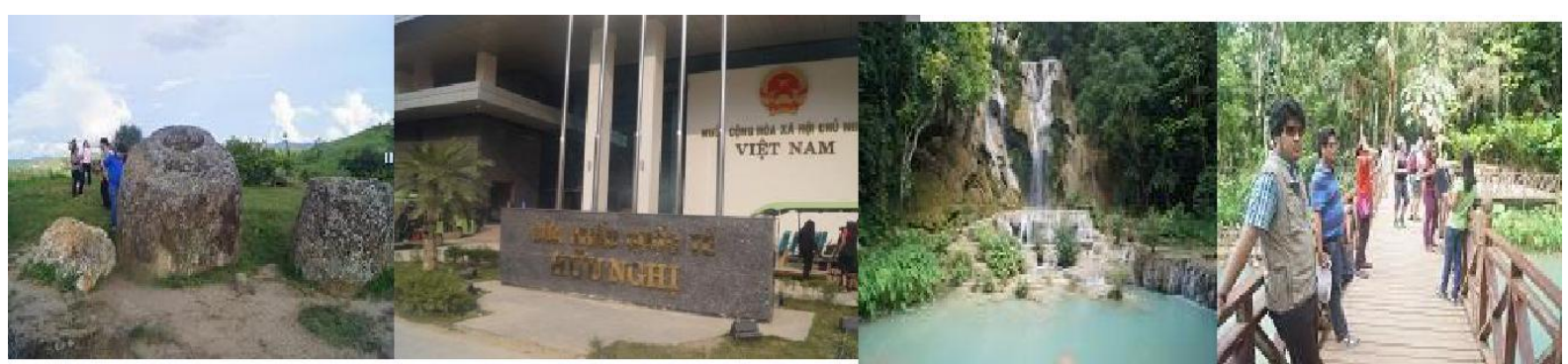

Fig. 3: The road conditions, customs system and features of Tourism.

\subsection{The general conditions of Loei province's Tourism supply chain:}

The value of the export of Thai-made Tourism through the Thali checkpoint has constantly risen, for this sort of goods is popular with Lao consumers. The consumers in Laos prefer the goods from Thailand to those from China or Vietnam whose prices are cheaper yet whose qualities are inferior to those of the Thai goods. Besides, Laos still cannot produce these goods itself. Lao people coming through the border checkpoint to purchase the goods can be divided into two groups: 1) Those coming to buy retail for household consumption. This group of consumers travel across the border to purchase goods at the Thali checkpoint where a market fair is organized on Saturdays or at large stores, Tesco Lotus, Big C supercenter, Makro, or Home Pro in downtown Loei. 2) Lao business operators entering the border to buy the goods wholesale to sell on back in their country. These traders travel in their own vehicles (pick-up trucks or six-wheel trucks) since their purchasing strategy is not to buy goods from merely one specific Thai operator, but to choose one that offers the best deals in terms of both price and credit. Presently, orders are mostly placed via Line chatting program. 80 percent of the Thai-made goods sold in Sayabouly province, 80 percent sold in Paklay city, and 20 percent sold in Luang Prabang are delivered through the Thali checkpoint (The goods sent to Luang Prabang are mostly transported through the checkpoint in Nong Khai to Vientiane and then to the city.) Some of the Thai merchandise is distributed to Vietnam and China as well. The assessment of the potential of the Tourism supply chain through the Thali checkpoint based on the SCOR model concerned two groups of parties in Loei province namely Thai wholesalers and their Lao counterparts. The details on this are as follows:

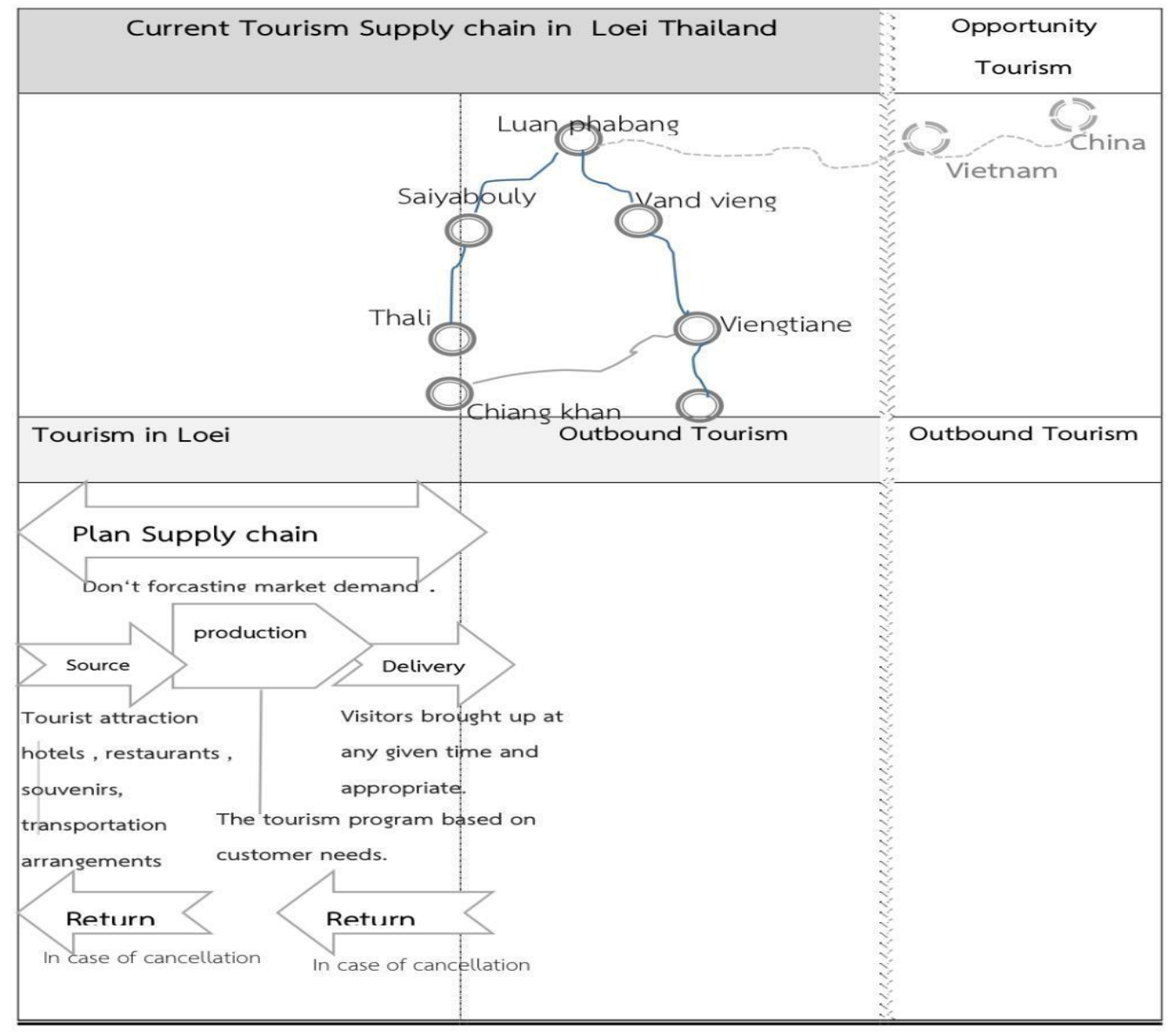

Fig. 4: Loei Tourism supply chain activities based on the SCOR model. 
3.3 The of the demand through strengths, weaknesses, opportunity and threats:

The strengths include the evident potential of the regional economic connectivity policy, strong demand for Tourism in Laos, Vietnam and China, and the better quality of Thai goods and service (Tourism) compared to those from the other countries. The weaknesses, on the other hand, are that the infrastructure for transportation such as road and customs systems is not good enough and that the trade conditions set by each country are not in accordance with one another. Regarding the opportunities, the regional connectivity policy has been intensified. That is, the markets in ASEAN and China will allow Thai goods, especially fruit and tourism, to be connected more easily with tourist cities in the region as well as to enter several more bigger markets. The key threat to the regional economy and the Tourism supply chain is, however, the uncertainty of the trade partner countries' rules and regulations, for instance the investment laws and import and export laws.

\section{Conclusions:}

According to the study focusing on the economic connectivity and Tourism supply chain from Loei province to Laos PDR, Vietnam and China, it was found that further progress has been made in the area of connectivity development through several cooperative frameworks, for example AEC, GMS and the economic corridors. This has contributed to the economic expansion along the trade routes linked to one another. The flow of goods, particularly Tourism, on emerging routes is fostered by such contributing factors as the transportation system, customs system as well as the establishment of business networks in the form of supply chains encompassing upstream, midstream and downstream supply chains. The majority of Thai-made Tourism tends to flow to Laos PDR; only a small quantity of them reaches Vietnam. As regards future trade opportunities, Thai fruit and tourism have the potential to flow to Vietnam and Nanning, Southern China. It is advisable in terms of policy that the government and private sector foster the economic connectivity on the routes connecting the major economic corridors. They should also promote goods with the potential for export, enhance the competitiveness of export operators and set up goods distribution centers as well as special economic zones near border provinces. Furthermore, service systems for economic connectivity and logistics need to be developed to become more effective in future.

\section{REFERENCES}

[1] Prapinit, P., 2015. The Trade Supply Chain Central North of Thailand - Laos PDR-Social Republic of Vietnam - Republic of China. The Thailand Research Fund, Bangkok, Thailand.

[2] Lapide, L., 2000. What About Measuring Supply Chain Performance?. Achieving Supply Chain Excellence through Technology, 2: 287-297.

[3] Choprva, sunil, and Peter Meindl, 2001. "Supply Chain Management : Strategy,Planning and Operations", Upper Saddle River,NJ:Prentice-Hall, Inc.

[4] Beamon, B.M., 1999. Measuring supply chain performance. Journal of Operations \& Production Management, 19: 275-292.

[5] Melan, M., 2016. Seamless Freight Movements at Check points of Bukit Kayu Hitam Malaysia and Sadao Thailand, WSCOM Publ., 1: 198-208. 